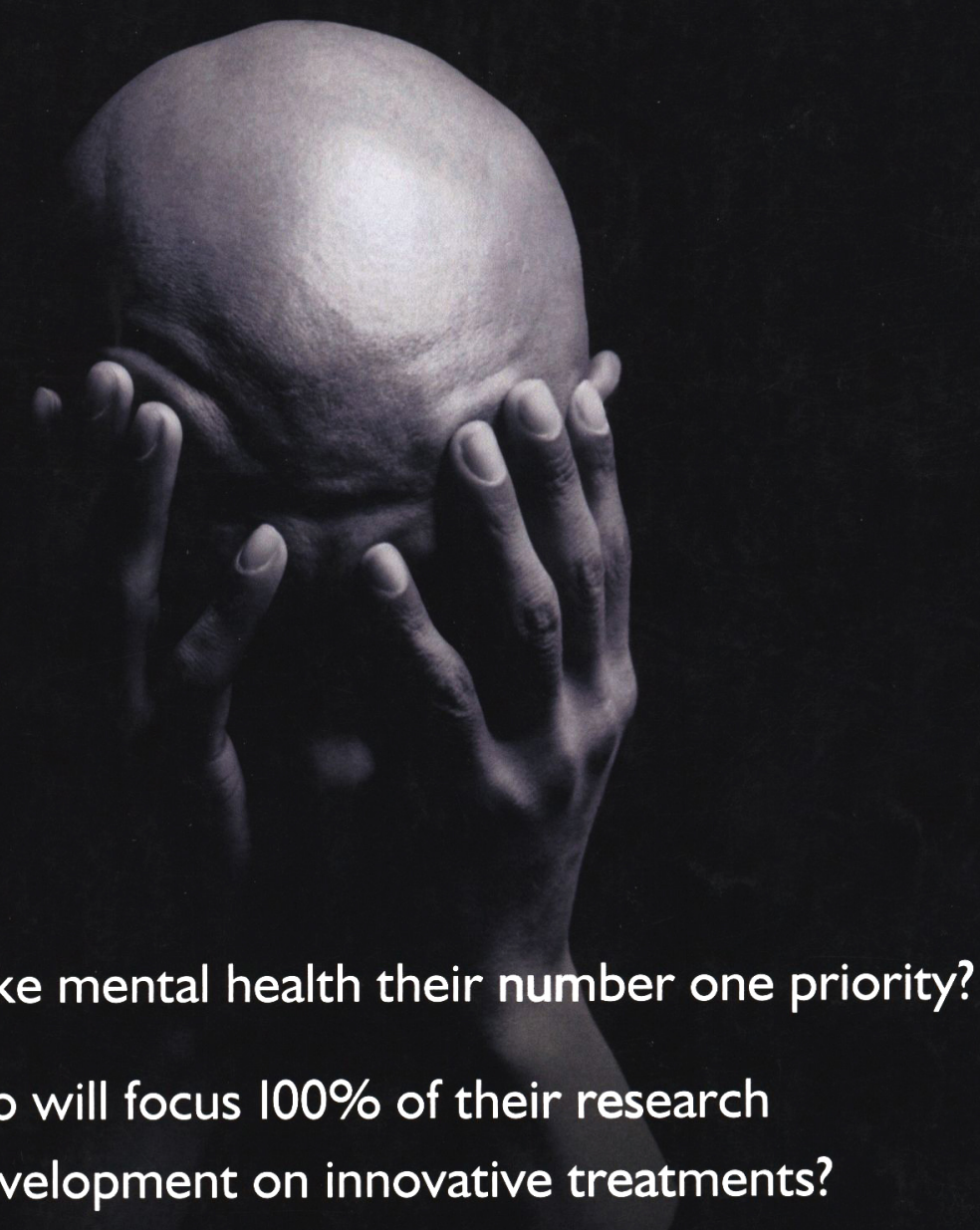

Who will constantly look for ways to support patients and caregivers?

Who will partner with mental healthcare professionals with an unprecedented commitment?

\title{
WE WILL.
}

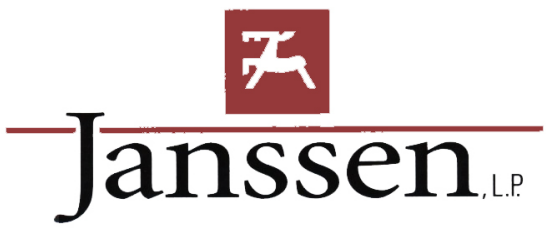

Exclusively dedicated to mental health

Please visit our Web site at www.janssen.com 